\title{
Efeito da centrifugação e do líquido prostático homólogo na criopreservação de espermatozoides epididimários caninos
}

\author{
[Effect of centrifugation and homologous prostatic fluid on canine epydidimal \\ spermatozoa cryopreservation] \\ M.I.V. Melo, J.V.S. Oliveira, G.R. Valle, M.A. Rachid, F.C.G. Soares, J.J.R.T. Matos \\ Curso de Medicina Veterinária - PUC Minas \\ 32604-115 - Betim, MG
}

\begin{abstract}
RESUMO
Realizaram-se dois experimentos de criopreservação de espermatozoides epididimários caninos, investigando-se o efeito da centrifugação e da adição do líquido prostático sobre as características físicas do espermatozoide pós-descongelação. No experimento I, foi testado o efeito da centrifugação. As amostras congeladas sem centrifugação apresentaram pós-descongelação: motilidade total (MT) de $26,7 \pm 21,2 \%$, motilidade progressiva (MP) de $21,2 \pm 20,1 \%$ e vigor espermático (V) de 2,2 $\pm 1,3$, e as

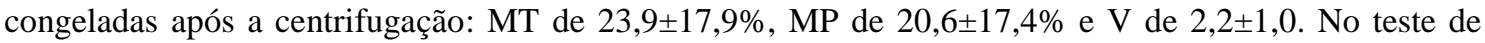
termorresistência, o período médio de duração com MT mínima de $10 \%$ foi de $165 \pm 21,2$ minutos sem centrifugação e de 77,5 $\pm 63,6$ minutos para as centrifugadas, indicando maior longevidade espermática das amostras não centrifugadas. No experimento II, foi avaliado o efeito da adição de líquido prostático homólogo no meio diluidor. As amostras congeladas sem líquido prostático no meio diluidor apresentaram MT de 13,3 $\pm 13,1 \%$, MP de $10,9 \pm 11,4 \%$ e $\mathrm{V}$ de $2,1 \pm 1,2$, e as congeladas com líquido

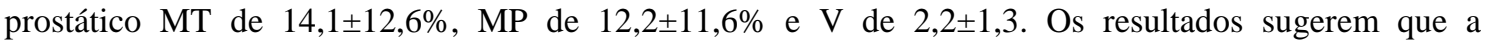
centrifugação e a adição de $10 \%$ de líquido prostático ao diluidor não tiveram efeito sobre as características físicas do espermatozoide epididimário canino pós-descongelamento.
\end{abstract}

Palavras-chave: cão, criopreservação, espermatozóide epididimário

\begin{abstract}
The effect of centrifugation and the prostatic fluid addition were evaluated on the physical characteristics of the cryopreserved canine epydidimal spermatozoa. In the first experiment, the effect of centrifugation was analysed. The samples without centrifugation showed $26.7 \pm 21.2 \%$ of total motility (TM), $21.2 \pm 20.1 \%$ of progressive motility (PM), and $2.2 \pm 1.3$ of intensity of movement (I). In addition, the samples after centrifugation showed $23.9 \pm 17.9 \%$ of TM, 20.6 $\pm 17.4 \%$ of $P M$, and $2.2 \pm 1$ of $I$. The mean time of samples duration, at least with $10 \%$ of total motility, was $165 \pm 21.2$ min without centrifugation and $77.5 \pm 63.6 \mathrm{~min}$ with centrifugation during the thermal resistance test. It suggests a better spermatic longevity in samples without centrifugation. In the second experiment, the effect of the prostatic fluid addition was evaluated. The samples cryopreserved without prostatic fluid showed $13.3 \pm 13.1 \%, 10.9 \pm 11.4 \%$, and $2.1 \pm 1.2 \%$ of $T M, P M$, and I, respectively. Furthermore, the samples with prostatic fluid showed $14.1 \pm 12.6 \%$, $12.2 \pm 11.6 \%$, and $2.2 \pm 1.3 \%$ of TM, PM, and I, respectively. These data support that centrifugation and $10 \%$ of prostatic fluid addition does not induce any effect on the physical characteristics of canine epydidimal spermatozoa cryopreserved.
\end{abstract}

Keywords: dog, cryopreservation, epydidimal spermatozoa

Recebido em 28 de fevereiro de 2009

Aceito em 10 de maio de 2010

E-mail: bel.melo@terra.com.br 


\section{INTRODUÇÃO}

A recuperação de espermatozoides colhidos diretamente do epidídimo, após a morte do animal, é um procedimento importante para se obter reserva de material genético de animais domésticos e de espécies em extinção. Experimentos têm sido realizados em várias espécies animais com o intuito de determinar o período ideal entre o óbito e a colheita dos espermatozoides (Yu e Leibo, 2002), o método de recuperar os espermatozoides do epidídimo após a morte de um animal (Sirivaidyapong, 2002), e mais diretamente sobre o processamento para o resfriamento e a congelação dos espermatozoides.

Ao comparar a qualidade do espermatozoide epididimário canino obtido por diferentes métodos, Sirivaidyapong (2002) concluiu que a lavagem que utilizou a introdução de uma agulha na parte proximal do ducto deferente foi mais eficiente que cortes repetidos do epidídimo em placa de Petri. Além disso, foi testada a adição de fluido prostático na proporção de 1:1 após descongelamento, o que aumentou significativamente a motilidade espermática no primeiro momento de avaliação, com drástico declínio após três horas de incubação.

England e Allen (1992) sugeriram efeito deletério do líquido prostático sobre as características do espermatozoide canino e afirmaram que, na cobertura natural, o tempo de contato do espermatozoide com o líquido prostático é reduzido.

Nöthling et al. (2007) estudaram o efeito do líquido prostático homólogo adicionado antes, depois e nesses dois tempos da criopreservação do espermatozoide epididimário canino processado em dois diferentes diluidores, BilEq e Andromed. Concluíram que o melhor procedimento para incrementar a motilidade espermática foi o de utilizar o diluidor BilEq com a adição de líquido prostático antes e depois da descongelação.

Em se tratando de espermatozoides epididimários, que não tiveram contato com o plasma seminal, torna-se importante investigar o efeito do contato desses espermatozoides com o líquido prostático antes de proceder à criopreservação. Os objetivos deste experimento foram investigar os efeitos da centrifugação e da adição do líquido prostático ao meio diluidor Tris-gema de ovo antes da congelação sobre a qualidade pós-descongelação do espermatozoide epididimário canino e estabelecer um protocolo eficiente e simples para essa espécie.

\section{MATERIAL E MÉTODOS}

A pesquisa foi realizada em duas etapas. No experimento I, foi testado o efeito da centrifugação e, no experimento II, foi avaliado o efeito da adição de líquido prostático homólogo na criopreservação do espermatozoide epididimário canino. Nas duas etapas, foram utilizados testículos e epidídimos de animais sem raça e idade definidas, provenientes de captura por um centro de controle de zoonoses, os quais foram sacrificados seguindo rígido protocolo ético. Os testículos e epidídimos foram retirados e pesados em balança de precisão. Os epidídimos dissecados foram imediatamente embalados em plástico e armazenados a $5^{\circ} \mathrm{C}$ no período médio de 24 horas para posterior recuperação e congelação dos espermatozoides, considerando esse tempo o suficiente para o envio do material a um laboratório, em situações reais.

Após a pesagem, foram retirados dos testículos fragmentos das regiões central e extremidades capitata e caudata para análise histológica. Os fragmentos colhidos foram fixados em solução de Bouin por 24 horas à temperatura ambiente. Em seguida, foram desidratados em séries crescentes de álcool etílico, diafanizados em xilol e processados rotineiramente para inclusão em parafina. Cortes de $4 \mu \mathrm{m}$ de espessura de cada fragmento foram corados pela técnica de hematoxilina-eosina. As lâminas obtidas foram avaliadas ao microscópico óptico e classificadas como: sem alterações; com alterações do desenvolvimento, degenerativas e alterações inflamatórias ou neoplásicas ou alterações quanto à fase de desenvolvimento sexual.

A hipoplasia testicular, quando detectada, foi classificada como: moderada (parcial), intermediária e grave (total), de acordo com Nascimento e Santos (2003); os processos degenerativos, quando presentes, em graus leve, moderado e grave; os inflamatórios, em graus I (leve), II (moderado) e III (intenso); e os neoplásicos de origem testicular, classificados de acordo com a WHO Classification de 1998 (Kennedy et al., 1998). 
No experimento I, foram processados 12 pares de epidídimos. A recuperação dos espermatozoides foi feita por meio de secções seriadas na cauda do epidídimo e de lavagem da área de cortes, em placa de Petri, com $3 \mathrm{~mL}$ do meio diluidor Trisgema de ovo com $6 \%$ de glicerol. Todo esse procedimento foi realizado sobre placa aquecedora a $38^{\circ} \mathrm{C}$. Após esse procedimento, o conteúdo da placa de Petri foi recuperado, e o seu volume medido. A amostra recuperada foi avaliada quanto à motilidade total (MT), à motilidade progressiva (MP) e ao vigor espermático (V). Compararam-se (teste t) a MT, a MP e o V antes do resfriamento, a fim de confirmar a semelhança entre as amostras provenientes dos epidídimos direito e esquerdo.

Os espermatozoides recuperados do epidídimo direito foram utilizados como grupo-controle (congelação sem prévia centrifugação), e os recuperados do epidídimo esquerdo foram congelados após centrifugação. No procedimento do epidídimo direito (tratamento $1=$ Tmt 1 ) após a recuperação dos espermatozoides, as amostras, acondicionadas em palhetas de $0,5 \mathrm{~mL}$, foram imersas em água à temperatura ambiente e levadas para resfriamento em geladeira comercial até a temperatura desta atingir $5^{\circ} \mathrm{C}$, com taxa de resfriamento de $0,076^{\circ} \mathrm{C} /$ minuto. Posteriormente, as palhetas, congeladas segundo metodologia descrita por Silva et al. (2003), foram dispostas horizontalmente em uma caixa térmica de isopor por cinco minutos a $5 \mathrm{~cm}$ acima do nível de nitrogênio líquido e, então, foram imersas diretamente no nitrogênio e armazenadas à temperatura de $-196^{\circ} \mathrm{C}$, até descongelação e análise.

As amostras recuperadas dos epidídimos esquerdos (tratamento $2=\mathrm{Tmt} 2$ ) foram centrifugadas a $800 \mathrm{x}$ g por 10 minutos, e o sedimento ressuspendido até ser obtido volume igual ao recuperado no grupo-controle (Tmt 1), com o mesmo meio diluidor. Após a avaliação da MT, da MP e do V, as amostras foram resfriadas e congeladas em igual procedimento ao do Tmt 1.

Todas as palhetas, descongeladas a $38^{\circ} \mathrm{C}$ por 30 segundos e avaliadas quanto à MT, à MP e ao V, foram submetidas ao teste de termorresistência lento (TTR) (Manual..., 1998), com leitura até $10 \%$ de MT.
Os dados obtidos mostraram distribuição normal. Foi considerada, para a análise estatística, a diferença entre os valores de MT, MP e V antes e após a descongelação. Os resultados foram comparados pelo teste $\mathrm{t}$ em amostras pareadas, a $5 \%$ de probabilidade, utilizando-se o programa Minitab versão 13.0. Os resultados do TTR foram apresentados em análise descritiva.

No experimento II, foram utilizados testículos e epidídimos de 17 cães. Foi seguido o mesmo procedimento geral já descrito para a avaliação histológica dos testículos e a obtenção dos epidídimos descritos no experimento I. Após a avaliação de MT, MP e V de cada amostra recuperada, o material obtido dos epidídimos direito e esquerdo foi misturado, constituindo um pool a ser dividido no grupo-controle (Tmt $1=$ sem líquido prostático) e no grupo tratamento (Tmt 2 = acrescido à amostra $10 \%$ de líquido prostático). Todo o procedimento foi realizado sobre placa aquecedora a $38^{\circ} \mathrm{C}$.

O líquido prostático foi obtido em etapa anterior a partir da colheita fracionada de sêmen de um cão adulto normospérmico, comprovadamente apto para a reprodução (Manual..., 1998). As frações pré-espermática e espermática do sêmen apresentaram volume de 3,1 mL com MT de $90 \%$ e V igual a 5. A terceira fração do ejaculado foi colhida separadamente, perfazendo um volume de 47,3mL e pH 6,5. Essa fração foi centrifugada a $800 \times$ g por 15 minutos, separada em alíquotas de $0,5 \mathrm{~mL}$ em eppendorf e congelada a $-15^{\circ} \mathrm{C}$ até sua utilização.

Procedeu-se ao envase e resfriamento do sêmen diluído conforme os tratamentos 1 e 2 , com taxa aproximada de $0,076^{\circ} \mathrm{C} /$ minuto e congelação da mesma forma que a descrita no experimento I. As palhetas foram descongeladas após um período mínimo de 10 dias de congelação, em banho-maria a $38^{\circ} \mathrm{C} / 30$ segundos, e avaliadas quanto à MT, à MP e ao V.

Os dados mostraram distribuição normal, não sendo necessária a sua transformação. Foi considerada para a análise estatística a diferença entre os valores de MT, MP e V, antes e após descongelação. Os resultados obtidos foram comparados pelo teste $\mathrm{t}$ em amostras pareadas, a $5 \%$ de probabilidade, utilizando-se o programa Minitab versão 13.0. Os resultados ao TTR foram apresentados em análise descritiva. 


\section{RESULTADOS E DISCUSSÃO}

No experimento I, foram trabalhados testículos e epidídimos de 22 animais. Destes, quatro $(18,2 \%)$ não apresentaram lesões dignas de nota, cinco $(22,8 \%)$ degeneração testicular leve, seis $(27,3 \%)$ degeneração testicular moderada, um $(4,5 \%)$ degeneração testicular de moderada a grave, quatro $(18,2 \%)$ hipoplasia testicular, um $(4,5 \%)$ leydigocitoma e $4,5 \%$ eram impúberes. Em epidídimos de oito animais, não foram recuperados espermatozoides ou os espermatozoides recuperados não apresentavam MT compatível com o processo de congelamento $(<10 \%$ MT). Somente $12 \quad(54,5 \%)$ animais puderam ser submetidos aos protocolos propostos, sendo estes os epidídimos respectivos aos testículos sem lesão digna de nota e com degeneração testicular leve e moderada e com espermatozoides recuperados com MT acima de $10 \%$.

A média de peso dos testículos direitos, cujos epidídimos foram utilizados como grupocontrole, foi de $10,53 \pm 5,28 \mathrm{~g}$, e a dos testículos esquerdos $9,86 \pm 4,04 \mathrm{~g}$.

Na Tab. 1, encontram-se os resultados de MT, MP e V das amostras recuperadas dos epidídimos esquerdo e direito, antes do resfriamento e após congelação. Observa-se a semelhança entre as amostras antes da destinação aos tratamentos 1 e 2 . É importante salientar que as amostras obtidas não estão dentro do padrão mínimo recomendado para se submeter um sêmen ao processo de criopreservação, entretanto, por se tratar de modelo para preservação de germoplasma de animais que vierem a óbito, esse material foi submetido ao processo de criopreservação. Hewitt et al. (2001), ao compararem a motilidade pósdescongelação de espermatozoides ejaculados com espermatozoides epididimários congelados com Tris-gema de ovo, concluíram que a motilidade do espermatozóide epididimário foi mais baixa (6-15\%) que a dos espermatozoides ejaculados $(56-68 \%)$. Esse valor mais baixo pode ser atribuído a diferenças morfológicas e funcionais entre espermatozoides ejaculado e epididimário, que influenciam a estabilidade das membranas, a susceptibilidade ao choque térmico e a resistência ao estresse osmótico, o que também pode justificar a baixa motilidade espermática das amostras trabalhadas. As diferenças entre os valores de MT, MP e V antes e após descongelação não foram significativas, indicando que a centrifugação não teve efeito sobre esses parâmetros (Tab. 1).

Tabela 1. Características físicas dos espermatozoides epididimários caninos antes do resfriamento e após descongelação com (Tmt 2) e sem centrifugação prévia (Tmt 1)

\begin{tabular}{llll}
\hline & MT $(\%)$ & MP $(\%)$ & V (1-5) \\
\hline Tmt 1 antes do resfriamento & $43,33 \pm 14,51$ & $32,92 \pm 13,89$ & $2,17 \pm 1,03$ \\
Tmt 2 antes do resfriamento & $44,17 \pm 15,05$ & $34,17 \pm 15,50$ & $2,92 \pm 0,52$ \\
Tmt 1 após descongelação & $26,67 \pm 21,25$ & $21,25 \pm 20,13$ & $2,17 \pm 1,27$ \\
Tmt 2 após descongelação & $23,92 \pm 17,87$ & $20,58 \pm 17,43$ & $2,17 \pm 1,03$ \\
\hline
\end{tabular}

Tmt 1: congelação de espermatozóides recuperados do epidídimo direito, sem centrifugação no preparo das amostras; Tmt 2: congelação de espermatozoides recuperados do epidídimo esquerdo, com centrifugação no preparo das amostras; MT: motilidade total; MP: motilidade progressiva; V: vigor espermático.

Os resultados obtidos antes do processamento das amostras e após descongelação revelam perda de, aproximadamente, $40 \%$ de motilidade durante todo o processamento dos espermatozoides. Vários autores têm sugerido, com êxito, a centrifugação de sêmen canino antes da criopreservação (Held, 1997; Strom Holst, 1999; Peña, 2000, todos citados por Cunha, 2002). Segundo Cunha (2002), imediatamente após a centrifugação, não há diferença significativa quanto à motilidade espermática entre os grupos, porém, após 30 minutos de incubação a $37^{\circ} \mathrm{C}$, os grupos centrifugados apresentam valores significativamente mais elevados. Neste experimento, a semelhança entre os resultados de MT, MP e V após a descongelação indica que a centrifugação antes da criopreservação não alterou a qualidade espermática dos espermatozoides epididimários caninos no processo de congelação, confirmando a hipótese de não haver necessidade da centrifugação por se tratar de espermatozoides que não tiveram contato com o plasma seminal. Phillips et al. (2007) referem-se à importância da retirada de fatores como células sanguíneas, urina, debris celulares, entre outros, que podem 
reduzir a fertilidade do sêmen. Em se tratando de espermatozoides recuperados diretamente do epidídimo, acredita-se que possa ocorrer contaminação da amostra com células sanguíneas e debris celulares, o que poderia ser reduzido com a centrifugação e, consequentemente, ter efeito benéfico sobre a qualidade espermática criopreservada. Entretanto, também esse possível efeito da centrifugação não foi constatado neste experimento.

O período médio de duração das amostras no TTR com MT mínima de $10 \%$ foi de $165+21,2$ minutos para as amostras sem centrifugação e de $77,5+63,6$ minutos para as processadas com centrifugação prévia ao resfriamento. A maior longevidade espermática das amostras não centrifugadas reforça a hipótese de ser desnecessária a centrifugação prévia à criopreservação em se tratando de espermatozoides epididimários caninos.

Dos 17 animais trabalhados no experimento II, $13(76,5 \%)$ tiveram seus epidídimos submetidos aos tratamentos, sendo estes os epidídimos respectivos aos testículos sem lesão digna de nota $(n=6,35,3 \%)$ e com degeneração testicular leve $(n=6,35,3 \%)$ ou moderada $(n=1,5,9 \%)$ à histopatologia, que apresentavam amostras de espermatozoides com características físicas compatíveis com o processo de congelação. Quatro animais não foram contabilizados, pois três $(17,6 \%)$ deles apresentaram hipoplasia testicular parcial ou total, e um $(5,9 \%)$ degeneração testicular de moderada a grave. O peso médio dos testículos cujos epidídimos foram utilizados foi de $9,9 \pm 2,9 \mathrm{~g}$.

As características físicas do pool de espermatozoides recuperados da cauda de epidídimos caninos direito e esquerdo, antes do resfriamento, foram: MT $32,7 \pm 17,9 \%$, MP $26,0 \pm 16,6 \%$ e V 2,4 40,6 da mistura do material obtido dos epidídimos esquerdo e direito, antes do resfriamento. Após essa avaliação, as amostras foram imediatamente envasadas $\mathrm{e}$ submetidas ao processo de resfriamento/congelação.

Na Tab. 2, encontram-se os resultados de MT, MP e $\mathrm{V}$ dos espermatozoides após descongelamento.

Tabela 2. Características físicas dos espermatozóides epididimários caninos pós-descongelação, processados com e sem líquido prostático

\begin{tabular}{lccc} 
& MT (\%) & MP (\%) & V (1-5) \\
\hline Tmt 1 & $13,3 \pm 13,1$ & $10,9 \pm 11,4$ & $2,1 \pm 1,2$ \\
Tmt 2 & $14,1 \pm 12,6$ & $12,2 \pm 11,6$ & $2,2 \pm 1,3$ \\
\hline
\end{tabular}

Tmt 1: congelado sem líquido prostático; Tmt 2: congelado com líquido prostático adicionado ao meio diluidor; MT: motilidade total; MP: motilidade progressiva; V= vigor espermático.

Houve perda relativa de aproximadamente $58 \%$ da MT, $54 \%$ da MP e $17 \%$ do $\mathrm{V}$ dos espermatozoides após o processo de congelação/descongelação, analisando-se todas as amostras, independentemente do tratamento ao qual foram submetidas. Essa perda foi maior que a verificada no experimento I. Deve-se considerar que, de maneira geral, a qualidade espermática trabalhada no experimento I foi melhor que a trabalhada no experimento II, o que pode ter contribuído para maior taxa de perda das características físicas.

England e Allen (1992) afirmaram que as frações pré-espermática e pós-espermática são originadas da próstata, a única glândula acessória dos cães, e citaram efeito deletério dessas frações sobre as características espermáticas. Explicaram, ainda, que na cobertura natural o tempo de contato do espermatozoide com essas frações é reduzido, diminuindo esse efeito. Esses autores pesquisaram o efeito da incubação dos espermatozoides caninos diluídos na primeira e terceira frações do ejaculado e afirmaram existir declínio no número de espermatozoides morfologicamente normais, decorrentes dos efeitos deletérios dessas frações. Rota et al. (1995) sugeriram uma possível vantagem de se usar espermatozoides recuperados diretamente do epidídimo por estes não terem sido expostos ao plasma seminal, que tem se mostrado deletério para a motilidade espermática e a fisiologia sob certas condições de armazenamento. Estudos mais recentes em várias espécies animais identificaram proteínas presentes no plasma seminal relacionadas à fertilidade (Souza, 2007).

Neste experimento, conclui-se que a adição de $10 \%$ de líquido prostático não teve efeito sobre 
as características físicas do sêmen pósdescongelamento (Tab. 2). Entretanto, deve-se investigar o efeito de maior volume de líquido prostático e do tempo de exposição dos espermatozoides ao meio diluidor adicionado de líquido prostático, antes do processamento de criopreservação.

Alguns experimentos de congelação do sêmen canino, sem a eliminação da primeira e da terceira fração, já foram propostos. Porém, os dados sugerem que a utilização unicamente da fração espermática gera melhores resultados (Peña, 1997, citado por Cunha, 2002). Para Farstad (1996), os diluidores do sêmen e os remanescentes do líquido prostático proporcionam condições osmóticas favoráveis, bem como energia aos espermatozoides durante o período de armazenagem entre resfriamento, equilíbrio e congelação. Os experimentos citados tratam de espermatozoides caninos ejaculados, o que não necessariamente deve ser esperado para espermatozoides epididimários.

Nöthling et al. (2007) relataram que a adição de líquido prostático homólogo para o processamento de espermatozoides epididimários caninos tem efeito benéfico e, se adicionado antes da criopreservação, inibe $\mathrm{o}$ desenvolvimento de reflexões da cauda. A adição do líquido prostático após o descongelamento aumentou a motilidade espermática até uma hora após o descongelamento. É importante ressaltar que as amostras trabalhadas por esses pesquisadores apresentavam características físicas do sêmen, antes do processamento, melhores que as trabalhadas neste experimento. Também o volume do líquido prostático adicionado diferiu entre os trabalhos, $20 \%$ do volume total no experimento realizado por Nöthling et al. (2007), o que pode promover resultados diferentes.

\section{CONCLUSÕES}

Os resultados sugerem o uso de um protocolo mais simples de congelação: que não são necessárias a centrifugação dos espermatozoides epididimários e a rediluição antes do resfriamento espermático, e que a adição de $10 \%$ de líquido prostático ao volume do diluidor não tem efeito sobre as características físicas do espermatozoide epididimário canino pósdescongelamento.

\section{REFERÊNCIAS BIBLIOGRÁFICAS}

CUNHA, I.C.N. Criopreservação do sêmen de cães. 2002. 144f. Tese (Doutorado) - Faculdade de Medicina Veterinária e Zootecnia, Universidade Estadual Paulista, Botucatu, SP.

ENGLAND, G.C.W.; ALLEN, W.E. Factors affecting the viability of canine spermatozoa II. Effects of seminal plasma and blood. Theriogenology, v.37, p.373-381, 1992.

FARSTAD, W. Semen cryopreservation in dogs and foxes. Anim. Reprod. Sci., v.42, p.251-60, 1996.

HEWITT, D.A.; LEAHY, R.; SHELDON, I.M. et al. Cryopreservation of epididymal dog sperm. Anim. Reprod. Sci., v.67, p.101-111, 2001.

KENNEDY, P.C.; CULLEN, J.M.; EDWARDS, J.F. et al. Histological classification of tumors of the genital system of domestic animals. Washington, DC: Armed Forces Institute of Pathology, 1998.

MANUAL para exame andrológico e avaliação de sêmen animal. 2.ed. Belo Horizonte: CBRA, 1998. 49p.

NASCIMENTO, E.F.; SANTOS, R.L. Patologia da reprodução dos animais domésticos. 2.ed. Rio de Janeiro: Guanabara Koogan, 2003.

NÖTHLING, J.O.; GERBER, D.; COLENBRANDER, B. et al. The effect of homologous prostatic fluid on motility and morphology of dog epididymal spermatozoa extended and frozen in Biladyl with Equex STM paste or Andromed. Theriogenology, v.67, p.264-275, 2007.

ROTA, A.; STRÖM, B.; LINDE-FORSBERG, C. Effects of seminal plasma and three extenders on canine semen stored at $4 \mathrm{oC}$. Theriogenology, v.44, p.885-900, 1995.

SILVA, A.R.; CARDOSO, R.C.S.; UCHOA, D.C. et al. Quality of canine semen submitted to single or fractionated glycerol addition during the freezing process. Theriogenology, v.59. p.821-829, 2003.

SIRIVAIDYAPONG，S. Motility and viability of canine epididymal sperm collected by differents methods. In: EVSSAR EUROPEAN CONGRESS ON REPRODUCTION IN COMPANION, EXOTIC AND LABORATORY ANIMALS. 3., 2002, Liege. Proceedings... Liege, 2002.

SOUZA, F.F. Proteínas do sêmen do cão são importantes ou não na fertilização? Rev. Bras. Reprod. Anim., v.31, p.108-114, 2007.

YU, I.; LEIBO, S.P. Recovery of motile, membrane intact spermatozoa from canine epididymides stored for 8 days at $4^{\circ} \mathrm{C}$. Theriogenology, v.57, p.1179-1190, 2002. 